\title{
PREVALÊNCIA DA VIOLÊNCIA CONTRA A MULHER NO NORDESTE: UMA QUESTÃO DE SAÚDE PÚBLICA
}

\section{PREVALENCE OF VIOLENCE AGAINST WOMEN IN THE NORTHEAST: A PUBLIC HEALTH ISSUE}

\section{Renata Torres Martins ${ }^{1}$, Igor de Sousa Gabriel ${ }^{2}$, Macerlane de Lira Silva ${ }^{3}$, \& Ocilma Barros de Quental ${ }^{4}$}

\author{
1234 Faculdade Santa Maria, Cajazeiras, PB, Brasil. \\ ${ }^{1}$ renatatorresmartins@ hotmail.com ${ }^{2}$ igorsgabriel@gmail.com ${ }^{3}$ macerlane@ hotmail.com \\ ${ }^{4}$ ocilmaquental2011@ @otmail.com
}

\section{ARTIGO INFO.}

\section{Recebido em: 10.11.2020}

Aprovado em: 07.12.2020

Disponibilizado em: 27.12.2020

Palavras-chave:

Violência; Mulher; Saúde Pública.

KEYWORDS:

Violence; Woman; Public health.

*Autor Correspondente: Martins, R. T.

\section{RESUMO}

Introdução: A violência contra a mulher é um fenômeno global que não respeita raça, religião ou classe social. É caracterizada pelo uso de palavras ou ações que machucam as pessoas e podem resultar em ferimentos, sofrimento e mesmo morte. É um grande problema social que não conhece barreiras geográficas e dissemina-se por todo o mundo. Objetivo: Analisar a prevalência da violência contra a mulher no Nordeste e seus impactos sobre a saúde pública. Metodologia: revisão integrativa da literatura, na qual foram utilizadas as bases de dados LILACS e SCIELO para pesquisa através dos Descritores em Ciências da Saúde. Como critérios de inclusão foram selecionadas as publicações em português e inglês, disponíveis na íntegra e compreendidas no recorte temporal dos últimos 7 anos. Conclusão: os resultados apontaram que a violência contra a mulher configura um grave problema social, mas que a cada dia se torna também um grave problema de saúde pública. Os serviços ofertados pela Atenção Primária à Saúde são imprescindíveis para a identificação de situações de violência contra as mulheres. Para que processo de identificação seja exitoso é preciso que os profissionais de saúde responsáveis pelo atendimento sejam adequadamente capacitados. Muitos médicos, enfermeiros e agentes comunitários de saúde não estão familiarizados com o tema. Há também profissionais que identificam prontamente a situação de violência, mas se sentem impotentes. Muito frequentemente a própria vítima não considera que a violência doméstica deva ser tratada e reconhecida como problema relacionado ao sistema de saúde.

\begin{abstract}
Introduction: Violence against women is a global phenomenon that does not respect race, religion or social class. It is characterized by the use of words or actions that hurt as people and can result in injury, suffering and even death. It is a major social problem that knows no geographical barriers and is spreading throughout the world. Objective: Analyze the prevalence of violence against women in the Northeast and its impacts on public health. Methodology: an integrative literature review, in which the LILACS and SCIELO databases were used for research through Health Sciences Descriptors. As inclusion criteria, they were selected as publications in Portuguese and English, available in full and included in the time frame of the last 7 years. Conclusion: the results showed that violence against women is a serious social problem, but that every day it also becomes a serious public health problem. The services offered by Primary Health Care are essential for the identification of occurrences of violence against women. For the identification process to be successful, it is necessary that the health professionals responsible for care are trained. Many doctors, nurses and responsible health workers are not familiar with the topic. There are also professionals who readily identify the situation of violence, but feel powerless. Very often, the victim does not consider that a problem of domestic violence should be analyzed and recognized as a problem related to the health system.
\end{abstract}




\section{INTRODUÇÃO}

A violência contra a mulher é um fenômeno global que não respeita raça, religião ou classe social e possui diferentes nuances. Segundo Coelho et al. (2014), a violência é caracterizada pelo uso de palavras ou ações que machucam as pessoas e podem resultar em ferimentos, sofrimento e mesmo morte. É um grande problema social que não conhece barreiras geográficas e dissemina-se por todo o mundo, inclusive nos países ditos desenvolvidos.

Em 2002 a Organização Mundial da Saúde (OMS) manifestou-se quanto à violência de forma contundente ao divulgar um relatório mundial sobre violência e saúde, definindo o problema como: uso intencional da força física ou do poder real ou em ameaça, contra si próprio, contra outra pessoa, ou contra um grupo ou uma comunidade, que resulte ou tenha qualquer possibilidade de resultar em lesão, morte, dano psicológico, deficiência de desenvolvimento ou privação.

Ainda segundo a OMS, 35\% das mulheres no mundo já sofreram violência física e/ ou sexual praticada por parceiro íntimo ou violência sexual cometida por não parceiro. Sendo assim, mais de uma a cada três mulheres no mundo já foi vítima de pelo menos uma ocorrência de violência.

A lei Maria da Penha (Lei n. 11.340/06) foi aprovada em 7 de agosto de 2006 pelo então presidente da República Luiz Inácio Lula da Silva, com o intuito de gerar meios que reprimissem a violência contra a mulher e garantir a estas uma proteção jurídica. A mesma publica que as violências doméstica e familiar praticadas contra a mulher incidem como infração aos direitos humanos. Além disso, ela declara a elaboração de políticas públicas para a garantia dos direitos da mulher.

O Mapa da Violência 2015 da Organização das Nações Unidas (ONU) revela que entre 1980 e 2013, 106.093 brasileiras foram vítimas de assassinato. De 2003 a 2013, o número de vítimas do sexo feminino cresceu de 3.937 para 4.762, ou seja, mais de $21 \%$ na década. Revela ainda que a taxa de aproximadamente 5 (cinco) homicídios para cada cem mil mulheres coloca o país na desconfortável quinta posição entre 83 (oitenta e três) países onde mais se matam mulheres simplesmente por serem mulheres, o que permite concluir que o patamar de violência contra a mulher no Brasil não arrefeceu, apesar da Lei Maria da Penha.

De acordo com dados extraídos do Sistema de Informações Sobre Mortalidade (SIM/Datasus), do Ministério da Saúde (MS), entre 1980 e 2014 o país registrou mais de 100 mil óbitos de mulheres por homicídios, o que representa uma taxa média de aproximadamente 5 óbitos por 100.000 mulheres. Na região Nordeste foi observado um incremento das taxas de homicídios e também da mortalidade por evento cuja intenção é indeterminada a partir de 1995, contrariando a tendência nacional.

Em 2017, a ONU Mulheres noticiou uma pesquisa que mostra que 27\% de todas as nordestinas com idade de 15 a 49 anos, já sofreram violência doméstica e $17 \%$ já foram agredidas fisicamente pelo menos uma vez. Natal, Fortaleza e Salvador foram consideradas as cidades mais violentas para as mulheres.

Portanto, como se percebe, nem sempre a violência é física, mas pode ser também psicológica. A violência psicológica é especialmente nociva por sua relativa "invisibilidade" em razão de 

nordeste: uma questão de saúde pública. Brazilian Journal of Production Engineering, 6(7), 150-172.

ocorrer geralmente em âmbito privado e também por não deixar marcas que se possa constatar por meio de um exame físico. Resulta da negação do carinho, ameaças de agressão física, obstáculos ao trabalho ou à profissionalização, restrição de amizades ou à liberdade de ir de vir, abuso verbal, insultos, humilhações, intimidação, isolamento ou desprezo.

A problemática que suscitou a elaboração deste estudo está relacionada ao fato de que, apesar da evolução das leis, a violência contra a mulher prossegue na sociedade moderna, pois como herdeira de uma cultura escravocrata ela é um produto cultural que não se apazigua meramente com sanções penais. É inegável que a inovação legislativa representou um grande avanço, contudo a previsão legal, frequentemente, encontra-se distante da realidade e falha na proteção das mulheres.

Toda esta violência acarreta grande prejuízo socioeconômico: as mulheres perdem anos potenciais de vida, há o impacto sobre o sistema jurídico e penitenciário e, especialmente importante para os propósitos deste estudo, termina afetando sobremaneira a saúde pública em função do sofrimento físico e psíquico que gera às vítimas e seus familiares.

Segundo Neto, et al., (2015) há tempos a OMS alerta para a necessidade de qualificar os profissionais de saúde para enfrentar adequadamente a questão da violência contra a mulher e combater a sua subnotificação, tendo em vista os obstáculos e óbices com os quais as vítimas se deparam para buscar ajuda, o que contribui para perpetuar a violência e para o incremento das taxas de feminicídio no país.

Indubitavelmente a violência contra a mulher, especialmente o feminicídio, representa um sério problema de saúde pública que abrange as mais diferentes classes sociais em todas as regiões do país, especialmente no Nordeste, onde é mais arraigada a cultura da "propriedade da mulher" pelo homem.

Desta forma, o objetivo geral deste trabalho é analisar a prevalência da violência contra a mulher no Nordeste e seus impactos sobre a saúde pública. Como objetivos específicos podese citar:

- $\quad$ Apresentar conceitos e definições sobre a violência;

- Explanar brevemente sobre os aspectos sociais, históricos e culturais da violência contra a mulher;

- $\quad$ Discorrer sobre as principais formas de violência contra a mulher;

- $\quad$ Analisar o impacto da violência contra a mulher na saúde pública.

A justificativa para a elaboração deste estudo repousa na necessidade de evidenciar a violência contra a mulher como causa significativa de morbidade e mortalidade das mulheres, destacando o problema como uma questão de saúde pública, almejando tornar sua abordagem entre os profissionais de saúde menos complexa e levando à uma reflexão acerca da organização do segmento para lidar com as mulheres em situação de violência. 

nordeste: uma questão de saúde pública. Brazilian Journal of Production Engineering, 6(7), 150-172.

\section{REFERENCIAL TEÓRICO}

\subsection{O Que é Violência?}

Segundo Nascimento (2004), a violência é caracterizada pelo uso de palavras ou ações que machucam as pessoas e podem resultar em ferimentos, sofrimento e mesmo morte. Para Viela (1997), violência é qualquer iniciativa que exerça coação sobre a liberdade de outrem, visando obstar sua liberdade de reflexão ou julgamento, rebaixando-o a um patamar de inferioridade.

A violência não é uma característica da sociedade moderna. Na verdade, a violência é uma fiel companheira do homem, presente ao seu lado desde sempre, porém manifesta-se de diferentes formas segundo o contexto histórico em que se apresenta. Na Idade Média, por exemplo, conhecida como a Idade das Trevas, muitos atos violentos foram praticados em nome de Deus. Atualmente, apesar do desenvolvimento da ciência, a "violência santa" continua em destaque, como fazem prova os atos terroristas praticados por fundamentalistas islâmicos (ver figura 1).

Figura 1. Ataque ao World Trade Center, Nova Iorque, 11 de setembro de 2001.

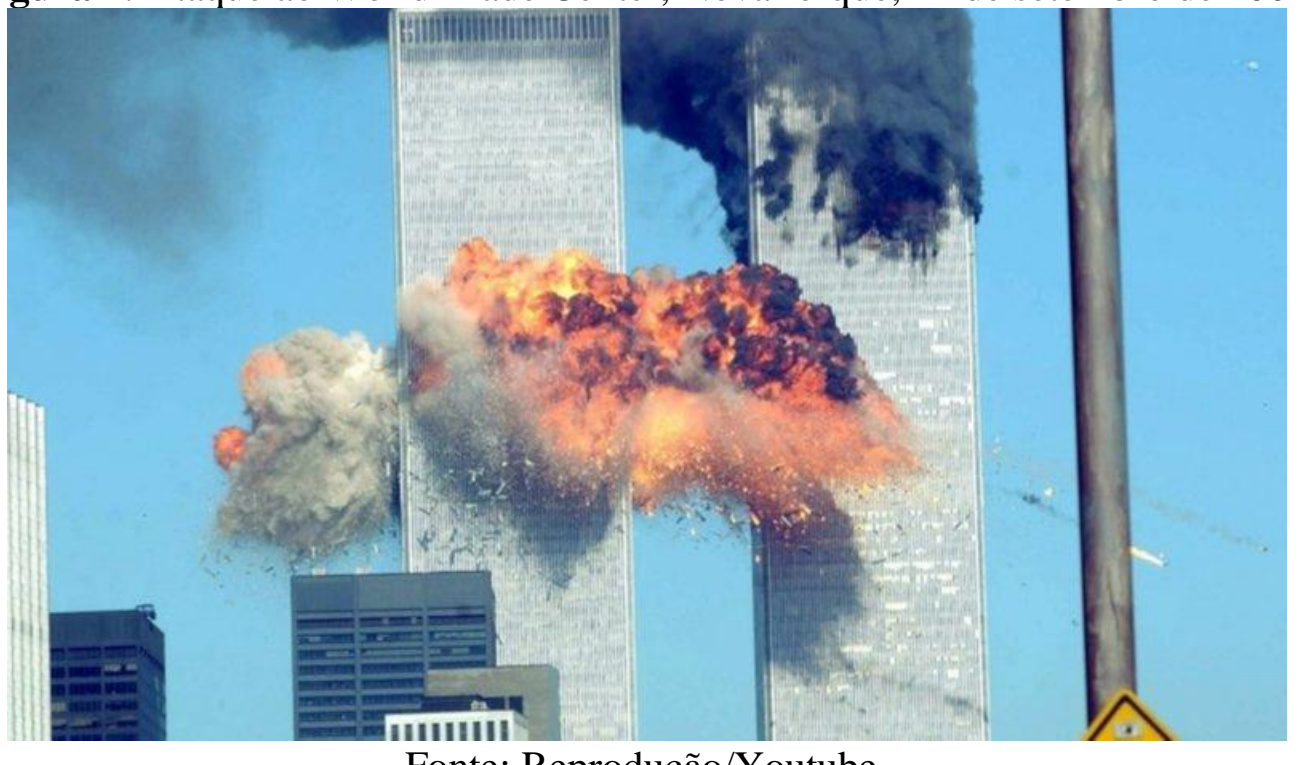

Fonte: Reprodução/Youtube.

Além desta modalidade de violência a sociedade contemporânea tem testemunhado o crescimento desmedido da violência juvenil e também a violência doméstica tem ganhado destaque. Para os propósitos deste trabalho é importante aprofundar os conhecimentos acerca da violência intrafamiliar e doméstica. Conforme Day et al., (2003) a violência doméstica pode ser definida como qualquer ato que acarrete sofrimento, danos físicos, sexuais ou psicológicos, incluindo a coerção e mesmo a privação da liberdade, através do cárcere privado. Para Amaral (2002) a violência doméstica ocorre geralmente no espaço privado, no próprio lar da vítima, pois dentro de casa não há testemunhas ou as testemunhas existentes são coagidas a silenciarem sobre a violência praticada, ou seja, no ambiente doméstico, por mais paradoxal que possa parecer, a mulher, a criança e o adolescente estão mais vulneráveis, até porque geralmente este tipo de violência tem como algoz alguém bem próximo das vítimas. Para se ter uma ideia da gravidade do problema, somente no Estado de São Paulo os casos de lesão corporal resultante de violência doméstica aumentaram 14\% nos últimos anos.

\section{@ $\odot \Theta \odot$}



nordeste: uma questão de saúde pública. Brazilian Journal of Production Engineering, 6(7), 150-172.

Figura 2. Lesão corporal causada pela violência doméstica em São Paulo.

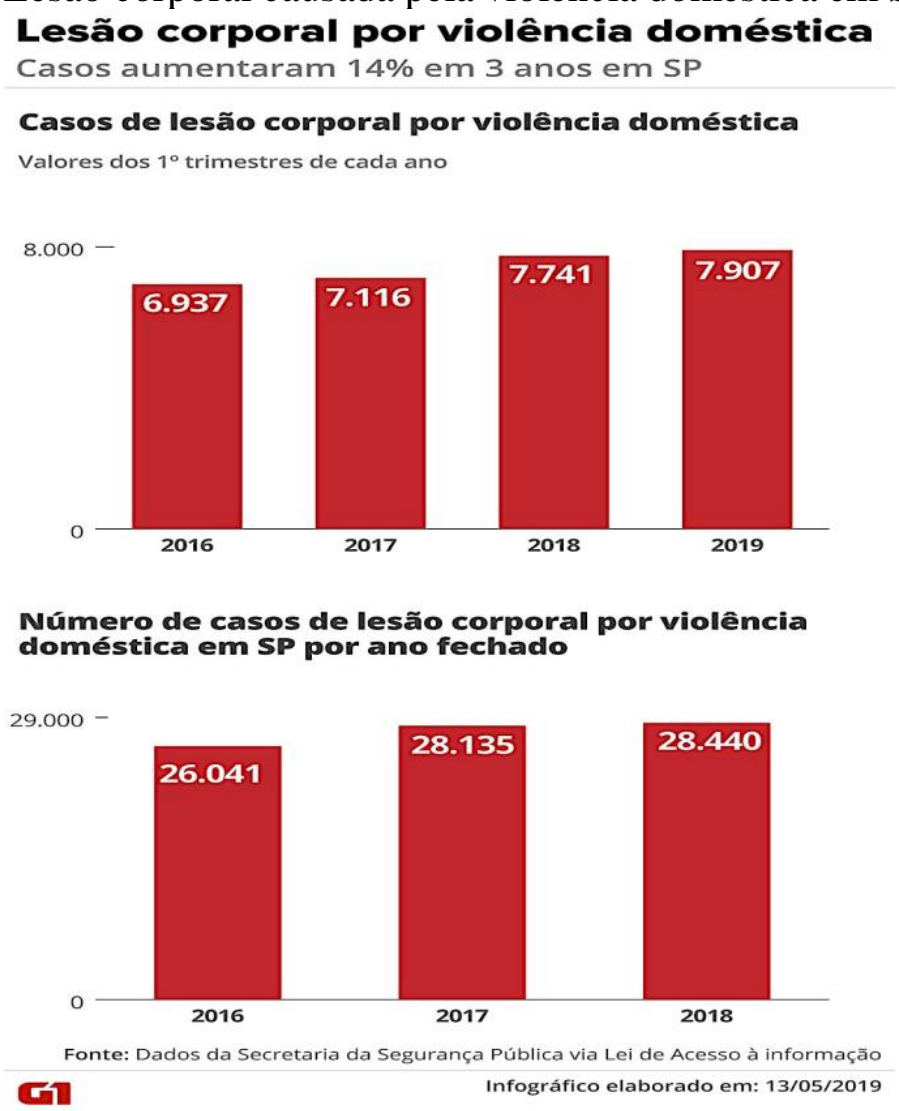

Segundo Borin (2007) a violência doméstica constitui uma das formas mais comuns e rotineiras de manifestação de violência contra as mulheres, crianças e adolescentes e, apesar de sua banalização, consegue permanecer relativamente invisível, pois ocorre dentro de casa e somente é testemunhada pelos moradores, os quais muitas vezes acham o fenômeno natural e de pouca importância. Conforme Bourdieu (2003) a casa, que deveria na realidade ser um lar (lugar de paz e harmonia) muitas vezes é o local ideal para atos de violência.

Especificamente acerca da violência contra a mulher, Leite e Lopes (2013) a definem como qualquer ato violento baseado no gênero, que resulte, ou tenha probabilidade de resultar, em dano físico, sexual, psicológico ou sofrimento para a mulher, incluindo a ameaça de praticar tais atos, a coerção ou privação arbitrária da liberdade em ambiente público ou privado.

Para Viana et al. (2018), a violência contra a mulher é um grave problema de saúde pública e é identificada como a ação ou a omissão baseada no gênero que cause morte, lesão, sofrimento físico, sexual ou psicológico e dano moral ou patrimonial.

Independentemente de sua definição ou de suas caraterísticas especificas a violência é onipresente na sociedade, apesar dos esforços de muitos para minimiza-la ou mantê-la afastada. Desta forma ela precisa ser discutida e enfrentada, qualquer que seja sua origem e manifestações.

\subsection{Aspectos Sociais, Históricos e Culturais da Violência Contra a Mulher}

A violência contra as mulheres, em todas as suas formas manifestas, faz parte da história da humanidade, variando em graus maiores ou menores de acordo com os contextos sociais,

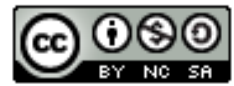


econômicos e culturais nos quais homens e mulheres estão inseridos e no modo como esses elementos se associam em suas vidas. Contudo, os atos ou ações de violência são percebidos de forma distinta entre as diversas sociedades ou mesmo entre segmentos sociais de uma mesma sociedade em decorrência da diversidade cultural (Ferreira, 2010).

Isto começou a mudar com o desenvolvimento da sociedade de classes, caracterizada pela busca do poder e consolidação da propriedade privada. Segundo Dias (2010), há aproximadamente 2500 anos consolidou-se a ideologia da superioridade masculina, com a submissão da mulher ao homem.

Nas civilizações Gregas, a mulher era vista como uma criatura subumana, inferior ao homem. Era menosprezada moral e socialmente, e não tinha direito algum (ver figura 3). Na Alexandria romanizada no séc. I d.C, Filón, filósofo helenista lançou as raízes ideológicas para a subordinação das mulheres no mundo ocidental. Ele uniu a filosofia de Platão, que apontava a mulher como tendo alma inferior e menos racionalidade, ao dogma teológico hebraico, que mostra a mulher como insensata e causadora de todo o mal, além de ter sido criada a partir do homem. Na Idade Média a mulher desempenhava o papel de mãe e esposa. Sua função precípua era de obedecer ao marido e gerar filhos. Nada lhe era permitido. (Dias, 2010, on line).

Figura 3. Condição feminina na Grécia Antiga.

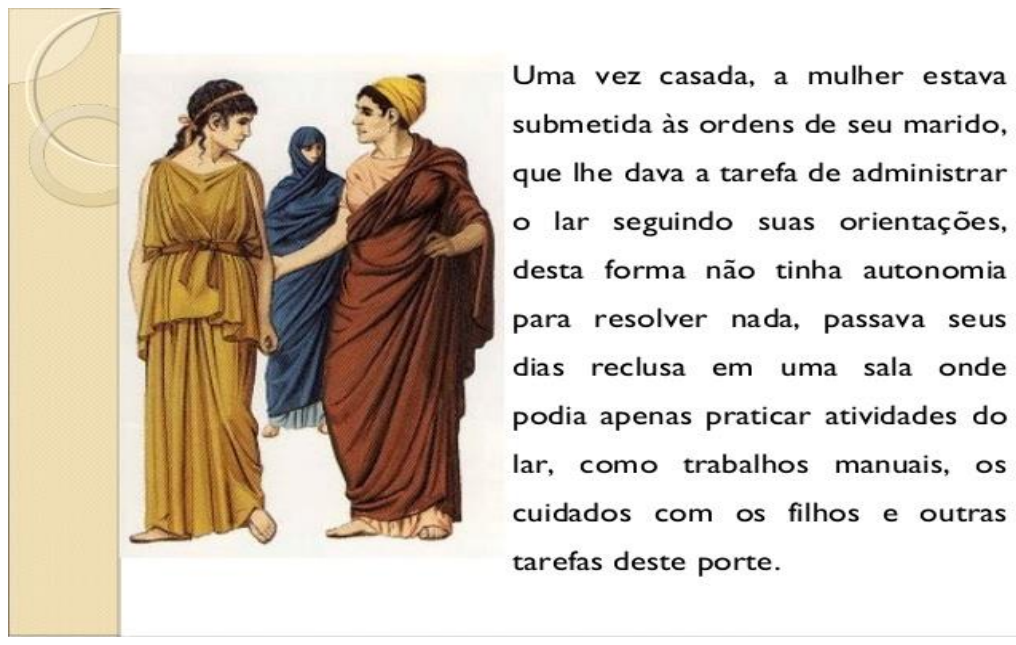

Fonte: https://www.slideshare.net/civilizao-grega-47345840

De acordo com Santiago e Coelho (2012), a palavra "família" origina-se do latim "famulus" e possui um sugestivo significado: servo ou escravo, o que indica que nas sociedades primitivas a família era tida como um conjunto de escravos que pertenciam a um senhor. Desta forma percebe-se que o casamento, instrumento para a constituição de uma família, foi no passado ambiente fértil para o exercício arbitrário do poder, guardando ainda hoje resquícios de outrora.

Conforme Rocha e Souza (2013), os fatores que acarretam a violência dos maridos ou companheiros contra suas mulheres ingressaram no Brasil ainda no período colonial, com as Ordenações Filipinas, obra do rei Felipe II da Espanha, que na época governava também Portugal, as quais deixavam bem explícitos os direitos do marido que flagrasse a mulher cometendo adultério: poderia legalmente matá-la e ao adúltero que achasse com ela, sem temer penalidade alguma. Este entendimento perdurou por séculos e apenas começou a alterar-se,

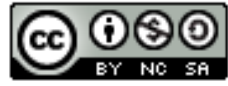



nordeste: uma questão de saúde pública. Brazilian Journal of Production Engineering, 6(7), 150-172.

timidamente, com a chegada da Corte Portuguesa ao Brasil em 1808 e introdução no do modelo de família burguesa: uma família limitada a pai, mãe e filhos, organizada em torno de uma severa divisão sexual de papéis, onde ao homem cabia o sustento da família e à mulher, a educação dos filhos e cuidados com o lar.

Nesse contexto, a evolução da família brasileira foi lenta e gradual. O Código Civil de 1916 defendia que o casamento era parte essencial central do direito de família, pois a tutela do Estado somente poderia amparar as famílias constituídas pelo vinculo indissolúvel do casamento. No Brasil, até 1962 a mulher era considerada relativamente incapaz e precisava da autorização do marido até mesmo para trabalhar (Dias, 2010).

Em 1977 a Lei do Divórcio consagrou a dissolução do vínculo matrimonial, mudando o regime legal de bens para o da comunhão parcial e tornando facultativa a adoção do nome do marido. Somente em 2005 o ordenamento jurídico pátrio revogou os incisos VII e VIII do art. 107, os arts. 217, 219, 220, 221, 222, o inciso III do caput do art. 226, o § 30 do art. 231 e o art. 240, todos do Decreto-Lei no 2.848, de 7 de dezembro de 1940 (Código Penal Brasileiro). Os incisos VII e VIII do art. 107 do Código Penal estabeleciam que o casamento da vítima com o agente era causa de extinção da punibilidade de crimes como estupro, atentado violento ao pudor; posse sexual mediante fraude, atentado ao pudor mediante fraude, sedução, corrupção de menores e rapto (arts. 213 a 221 do CP), pois imperava o entendimento que o casamento "limpava" a honra da vítima. Também em 2005 a Lei 11.106 extirpou o crime de adultério do Código Penal Brasileiro.

\subsection{Formas de Violência Contra a Mulher}

Conforme Krug et al (2002 apud Rosa, 2010), há três modalidades básicas de violência, segundo às características do agressor, a saber:

- Violência coletiva: atos de violência que caracterizam o domínio de certos grupos ou mesmo do Estado (terrorismo, genocídio, guerras, etc.);

- Violência auto infligida: caracterizada por suicídios, automutilações ou quaisquer outros abusos contra si próprio;

- Violência interpessoal: divide-se em violência comunitária (estupro por estranhos, violência juvenil, violência em prisões, etc.) e violência familiar (violência praticada pelo marido ou companheiro, abuso infantil ou contra os idosos).

Alves e Evanson (2013) destacam ainda a violência estrutural, relacionada às formas de dominação e opressão vigentes, vinculada a processos sociais, políticos ou econômicos que perpetuam a miséria e as desigualdades sociais e de gênero, permanecendo invisível por estar naturalizada permanentemente ao tecido social da sociedade moderna.

De acordo com Coelho et al. (2014), a violência igualmente pode ser dividida segundo a natureza de seus atos: abuso físico, psicológico, sexual e a que envolve abandono ou negligência. $\mathrm{O}$ abuso físico (uso da força física para produzir injúria ou dor), por sua vez, dividese em ato moderado (ameaças sem a utilização de armas, agressões contra animais, empurrões ou tapas) e ato severo (agressões que causam lesões temporárias ou permanentes, ameaças com arma, queimadura, etc.). Já o abuso psicológico é caraterizado por agressões verbais ou gestuais que buscam amedrontar, humilhar ou limitar a liberdade da vítima. $\mathrm{O}$ abuso sexual, por seu

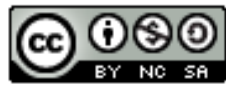



nordeste: uma questão de saúde pública. Brazilian Journal of Production Engineering, 6(7), 150-172.

turno, está relacionado à utilização da vítima para obter prazer de natureza erótica, enquanto o abandono é caracterizado pela total ausência ou recusa de cuidados a quem deles necessita.

Figura 4. Tipos de violência contra a mulher.
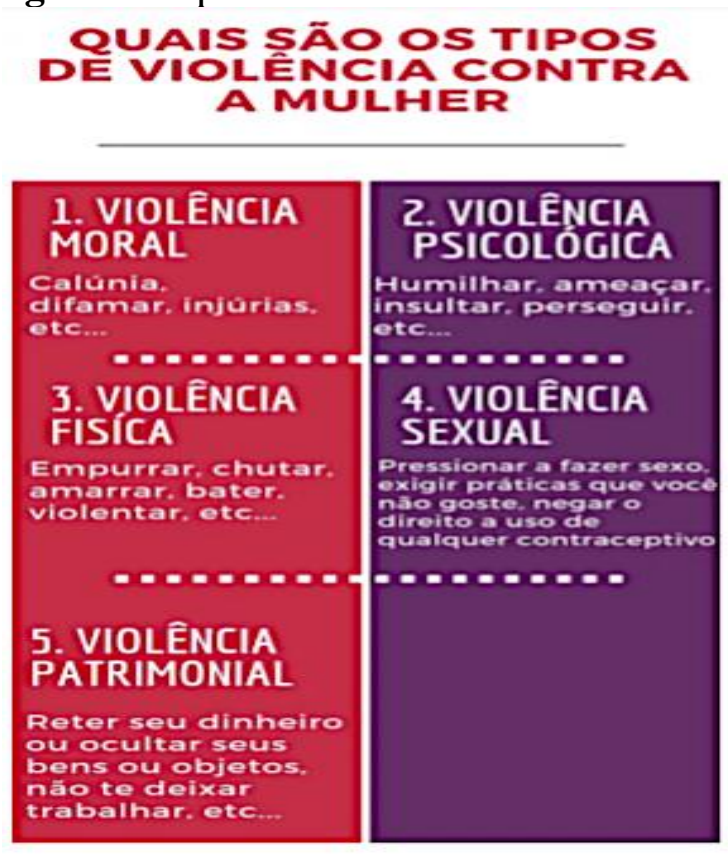

Conforme o Ministério da Saúde (2011), a violência também pode ser classificada de acordo contra o grupo contra o qual se dirige: violência intrafamiliar (qualquer ação ou omissão que prejudique o bem-estar ou o desenvolvimento de qualquer integrante da família. Pode ser cometida dentro ou fora de casa e mesmo por pessoas sem vínculos de consanguinidade), violência doméstica (tem restrição social e espacial, pois contempla apenas atos de violência no cenário doméstico), violência contra a mulher (violência especifica contra pessoas do sexo feminino, de natureza física, sexual ou psicológico), inclusive as ameaças de tais atos, a coação ou a privação da liberdade tanto na vida pública como na privada.

A lei Maria da Penha cunhou o termo "violência entre parceiros íntimos" para designar qualquer ato de violência (física, psicológica, sexual, moral, patrimonial, além do comportamento controlador) praticado em qualquer relacionamento íntimo de afeto, mesmo que não haja coabitação.

Coelho et al., (2014), alertam, entretanto, que alguns estudiosos demonstram preferência pelo termo "violência no casal" por abranger o antes, o durante e o depois de uma relação formal entre um casal homossexual ou heterossexual, podendo ocorrer dentro ou fora de casa.

\subsection{O Impacto da Violência Contra a Mulher na Saúde Pública}

Conforme Alves e Leal (2013), nos anos de 1980 a Associação de Psiquiatria Americana listou o Distúrbio de Stress Pós-Traumático (DSPT) como uma desordem psiquiátrica. Este distúrbio contribuiu para o reconhecimento das sequelas sofridas pelas mulheres vítimas de violência doméstica em seus lares. Segundo Tavares (2011) as vítimas de DSPT podem desenvolver traumas produzidos por meio de eventos únicos, sem repetição constante, do qual geralmente os indivíduos se recuperam ou como consequência de contínua exposição a situações de estresse. Neste último caso as sequelas podem durar anos e os principais sintomas são:

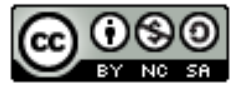


dissociação, depressão, pânico, ansiedade, etc. Para o referido autor estas vítimas têm um risco aumentado de desenvolver transtorno de estresse pós-traumático (TEPT), depressão maior, transtorno do pânico e abuso de substâncias. A elevada prevalência da violência contra a mulher, fato considerado como um problema de saúde pública, tem ensejado o interesse da sociedade devido aos graves problemas que podem ocasionar na vida da mulher e do impacto direto sobre sua saúde, quando não chega a causar a morte em consequência das lesões físicas ou emocionais (Lucena, 2017).

Estudo realizado por Silva e Oliveira (2015) revelou que a violência contra a mulher No Brasil apresenta elevada prevalência, colocando-se como problema prioritário a ser combatidos pela saúde pública e organismos de defesa dos direitos humanos. Para as referidas autoras, ao observar-se o contexto das vítimas, percebe-se a vergonha, o medo e o desconhecimento do arcabouço legal que impõe limites à violência. Esses fatores dificultam a ida das vítimas aos serviços de saúde. Mesmo quando se veem obrigadas a procurar esses serviços, devido à presença de lesões físicas, as mesmas tendem a silenciar o problema e raramente fazem queixas espontâneas durante as consultas. Isto proporciona um caráter de invisibilidade à violência de gênero, que não é algo consentido, mas sim cedido, em virtude de as mulheres não usufruírem plenamente do poder patriarcal, como ocorre com os homens (Tabela 1 e 2).

Tabela 1. Formas de violência.

\begin{tabular}{cc}
\hline Variável & Percentual \\
\hline Física, sexual e psicológica & $26,3 \%$ \\
\hline Física e psicológica & $14,9 \%$ \\
\hline Física & $12,8 \%$ \\
\hline Física e sexual & $7,4 \%$ \\
\hline Sexual & $6,1 \%$ \\
\hline Física, sexual, psicológica e patrimonial & $5,4 \%$ \\
\hline Física, psicológica, sexual e moral & $4,7 \%$ \\
\hline Psicológica & $2,0 \%$ \\
\hline Física, psicológica, sexual, moral e patrimonial & $2,0 \%$ \\
\hline Física, psicológica, moral e patrimonial & $1,4 \%$ \\
\hline Sexual e psicológica & $1,4 \%$ \\
\hline Física, psicológica e patrimonial & $0,7 \%$ \\
\hline Não referiu & $14,8 \%$ \\
\hline
\end{tabular}

Fonte: Silva, \& Oliveira, 2015.

Tabela 2. Consequências da violência.

\begin{tabular}{cc}
\hline Agravo & Percentual \\
\hline À saúde física e mental & $19,6 \%$ \\
\hline À saúde mental & $16,9 \%$ \\
\hline À saúde física & $11,5 \%$ \\
\hline À saúde física, mental e sexual/reprodutiva & $6,8 \%$ \\
\hline À saúde física, mental e sexual, bem como à saúde de outros & $3,4 \%$ \\
\hline Á saúde física e mental, bem como à saúde de outros & $2,0 \%$ \\
\hline À saúde sexual/reprodutiva & $2,0 \%$ \\
\hline À saúde física e sexual/reprodutiva & $1,4 \%$ \\
\hline À saúde de outros & $0,7 \%$ \\
\hline À saúde física, mental e social & $0,7 \%$ \\
\hline À saúde física, mental e social, bem como à saúde de outros & $0,7 \%$ \\
\hline À saúde física, bem como à saúde de outros & $0,7 \%$ \\
\hline Não referiu & $33,8 \%$ \\
\hline
\end{tabular}

Fonte: Silva, \& Oliveira, 2015. 
A violência contra a mulher têm consequências também na vida da sociedade, demostrando a alcance e dimensão do problema. Entretanto, existem empecilhos em prevenir tais episódios ou em agir nesse enfrentamento por fatos relacionados a questões culturais, educacionais e à insuficiência de serviços e profissionais capacitados para lidar com casos de violência (Leite, et al., 2014).

Constata-se, portanto, que a violência doméstica, notadamente a violência psicológica, acarreta inúmeros problemas de natureza emocional às mulheres que, não raras vezes, para tentar ocultar as cicatrizes indeléveis deixadas em sua psiquê recorrem ao uso de psicotrópicos na vã tentativa de ignorar os transtornos causados pelas ofensas continuas à sua autoestima. Trata-se, assim, de um grave problema de saúde pública que exige políticas públicas para o seu enfrentamento e prevenção.

Além dos transtornos psicológicos, a violência contra a mulher possui uma face ainda mais cruel: o feminicídio, influenciado por aspectos socioculturais, como visto anteriormente. Para Souza (2017), o termo femicídio ou feminicídio foi utilizado pela primeira vez na década de 1970, representando um termo de cunho legal e político, para conceituar seja qual for a demonstração de exercício de relações de desigualdade de poder entre homens e mulheres que resultem na morte de uma ou mais mulheres.

\section{METODOLOGIA}

\subsection{Tipo de Estudo}

Trata-se de uma revisão integrativa da literatura, que tem a finalidade de reunir e sistematizar resultados de pesquisas sobre um delimitado tema ou questão de maneira sistemática e ordenada, contribuindo para o aprofundamento do conhecimento do tema investigado (Mendes, Silveira, \& Galvão, 2013).

Por meio do processo de análise sistemática e síntese da literatura de pesquisa, a revisão integrativa bem elaborada pode representar o estado atual da literatura de pesquisa. Trata-se de um método que resume a literatura de um problema clínico ou fenômeno de interesse que incorpora múltiplas perspectivas e tipos de literatura. Esse método pode combinar dados de literatura teórica tanto quanto na literatura empírica (Mendes, Silveira, \& Galvão, 2013).

De acordo com Botelho, Cunha e Macêdo (2011), todo estudo de revisão integrativa da literatura deve seguir seis etapas distintas. A primeira dela é caracterizada pela questão norteadora, a pergunta para responder os objetivos do trabalho. A segunda etapa consiste em investigar, através da literatura, a amostra que a ser estudada. A terceira etapa é a coleta dos dados com base nas pesquisas bibliográficas. A etapa seguinte envolve a análise dos dados pesquisados. A quinta etapa trata da elucidação dos dados obtidos e a sexta, de sua caracterização em forma de uma revisão de literatura. O presente estudo terá como questão norteadora: Qual a prevalência da violência contra a mulher no Nordeste e qual seu impacto na saúde pública?

\subsection{Fontes de Busca de Dados e Estratégias de Seleção}

Os dados foram coletados na Biblioteca Virtual em Saúde utilizando-se os seguintes Descritores em Ciências da Saúde (DeCS): Violence against women and Domestic violence. A consulta 

nordeste: uma questão de saúde pública. Brazilian Journal of Production Engineering, 6(7), 150-172.

bibliográfica computadorizada será realizada de forma individual nas seguintes bases de dados: Scientific Electronic Library Online (SciELO), e Literatura Latino-Americana em Ciências de Saúde (LILACS). Esta escolha se justifica por se tratarem de bases confiáveis de abrangência nacional, atualizadas e relacionadas com a área da saúde.

\subsection{Definição dos Critérios de Inclusão e de Exclusão}

Nessa etapa foram estabelecidos os critérios de elegibilidade dos artigos a serem incluídos no estudo, ou seja, de inclusão e exclusão. Assim, como critérios de inclusão foram selecionadas as publicações em português e inglês, disponíveis na íntegra e compreendidas no recorte temporal dos últimos 7 anos (2013-2020). Foram excluídos os artigos em duplicidade nas bases de dados, cartas ao editor e teses e dissertações.

Para gerenciar a elevada quantidade de referências encontradas foi utilizada a ferramenta Start (State of the Art through Systematic Review), visando auxiliar no processo de aceitação ou rejeição dos estudos e sumarização dos resultados.

Figura 5. Etapas da Revisão sendo realizadas pelo StArt.

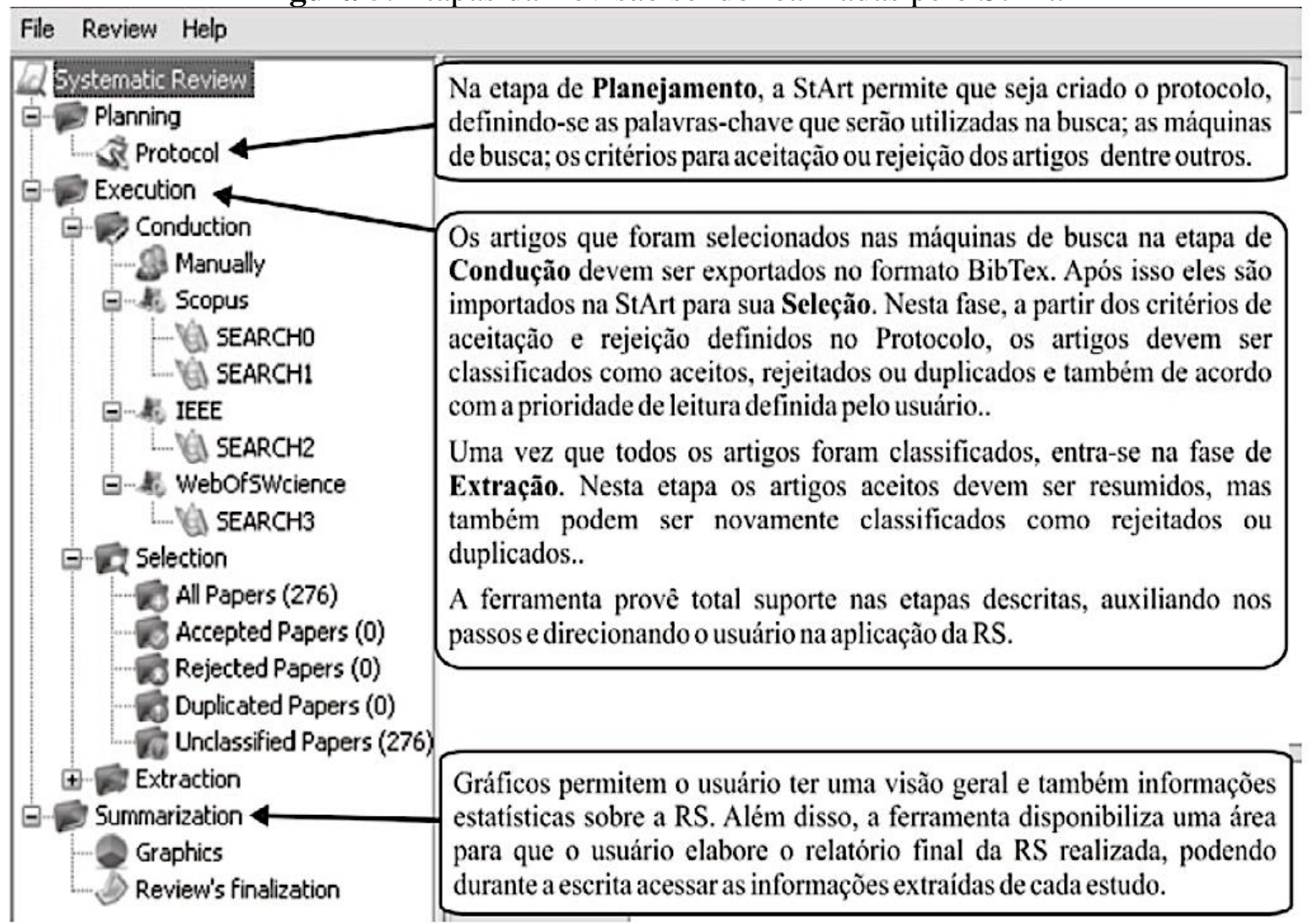

Fonte: Hernandes et al. (2010).

As figuras seguintes exibem a tela do inicial do software em destaque, a tela de identificação do estudo e da pesquisadora e a que descreve um resumo do estudo realizado. 
Citação (APA): Martins, R. T., Gabriel, I. de S., Silva, M. de L., \& Quental, O. B. de. (2020). Prevalência da violência contra a mulher no nordeste: uma questão de saúde pública. Brazilian Journal of Production Engineering, 6(7), 150-172.

Figura 6. Tela inicial StArt

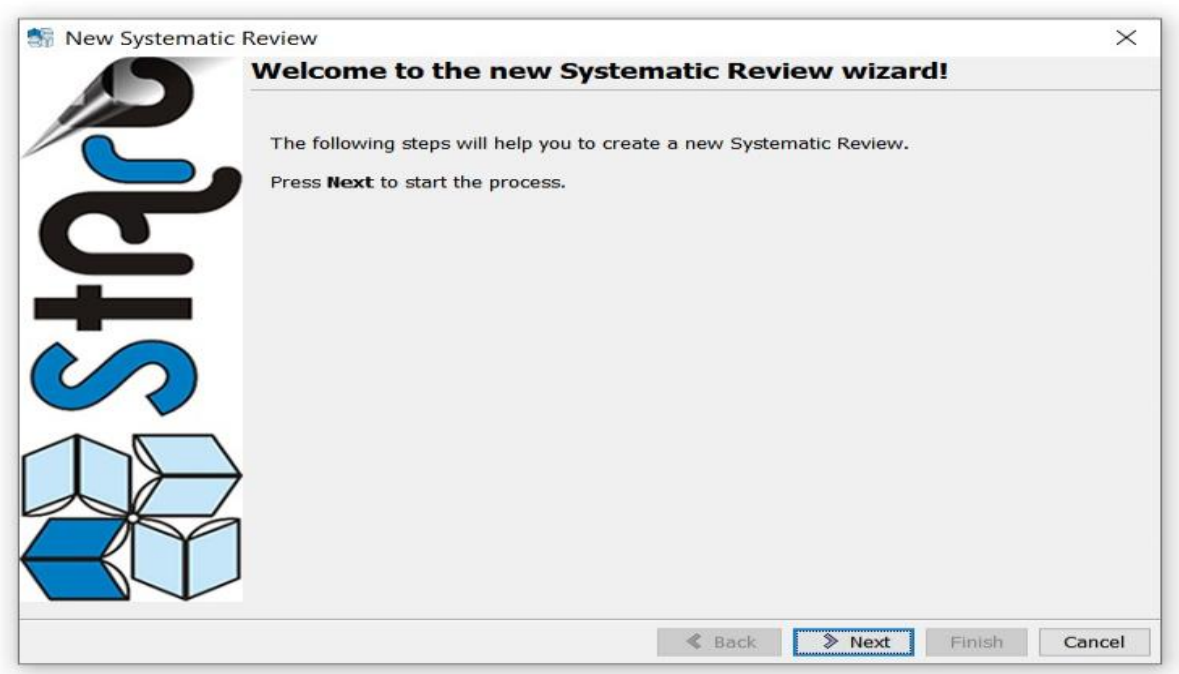

Fonte: Autores.

Figura 7. Tela de identificação do estudo.

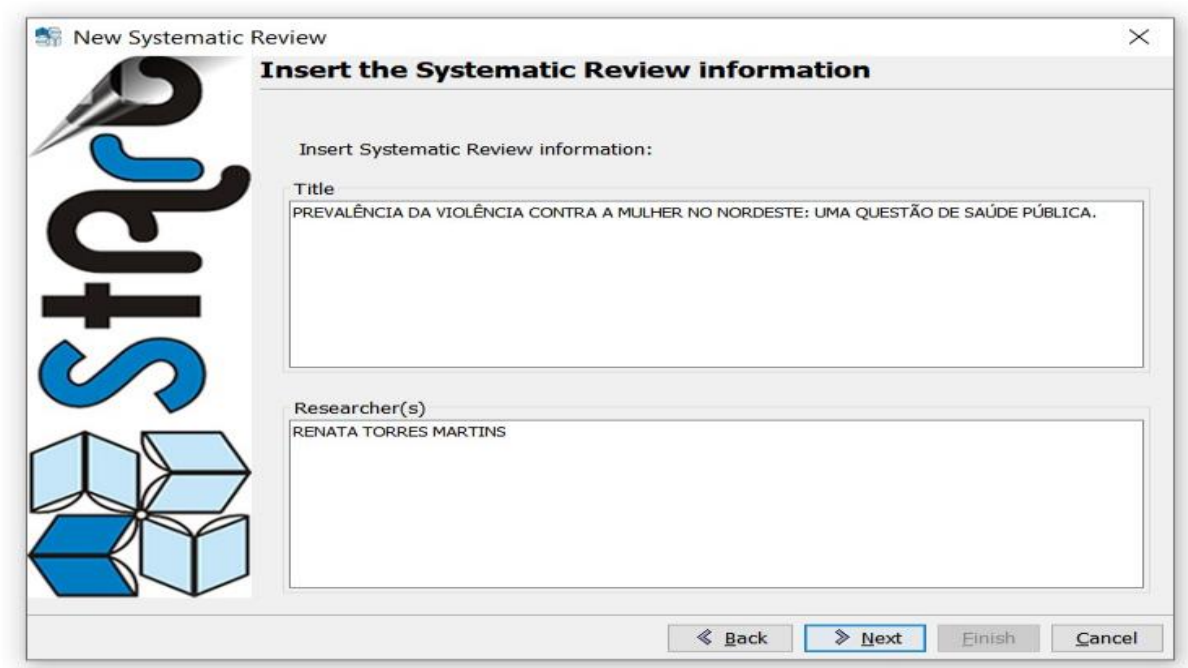

Fonte: Autores.

Figura 8. Descrição do estudo.

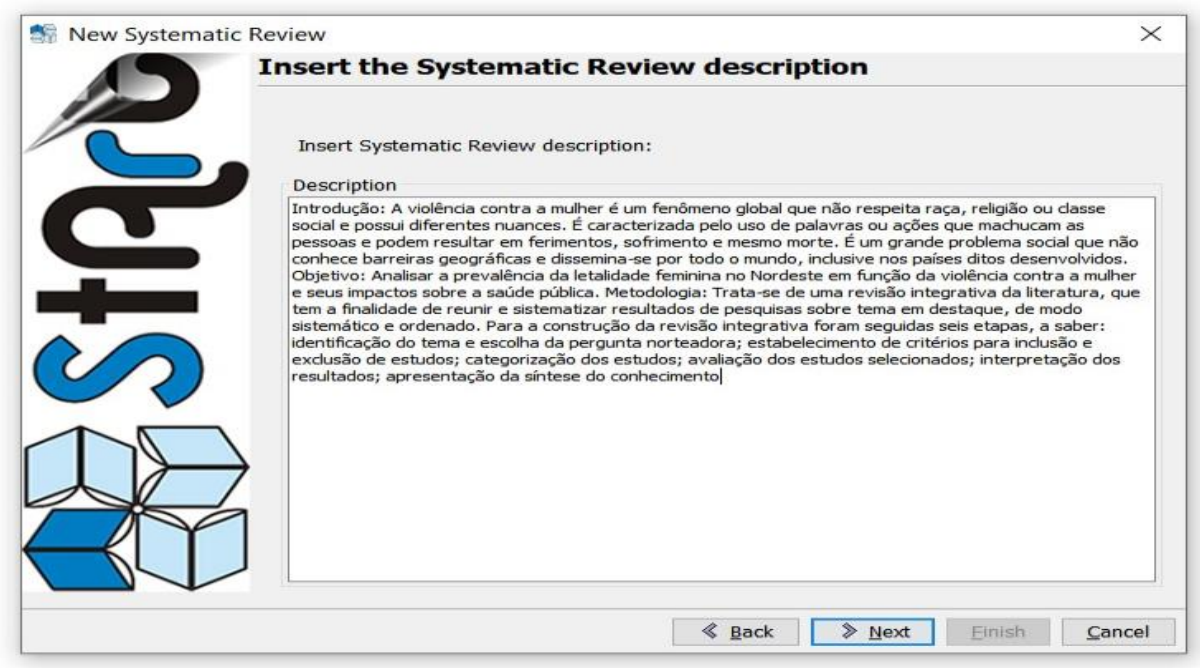

Fonte: Autores 

nordeste: uma questão de saúde pública. Brazilian Journal of Production Engineering, 6(7), 150-172.

\subsection{Avaliação dos Estudos Incluídos na Revisão}

Após seleção dos artigos, os mesmos foram organizados procedendo-se à identificação do periódico e ano de publicação, informações sobre os autores, objetivo e aspectos metodológicos dos estudos, pontos positivos e negativos das publicações. Posteriormente, à sequência das leituras mais profundas, foram feitos fichamentos para identificar os conceitos e definições chave trazidos pelos artigos.

\subsection{Interpretação dos Resultados}

Nessa etapa os artigos foram lidos minuciosamente e feitas anotações dos achados mais relevantes de modo a identificar os pensamentos semelhantes e os objetivos propostos de cada uma das pesquisas, para assim, fazer uma avaliação das conclusões dos estudos sobre o tema.

\subsection{Síntese do Conhecimento}

Nesta etapa foram descritas as principais conclusões dos autores, articulando-se suas linhas de pensamento dentro da temática do estudo. Serão reunidas as principais evidências trazidas pelos artigos selecionados, sintetizando-se os achados de forma a consolidar os dados existentes e sugerir novos estudos para preencher as possíveis lacunas na literatura.

\subsection{Artigos Selecionados}

Os estudos selecionados foram obtidos a partir dos passos ilustrados pelo fluxograma a seguir.

Figura 9. Processo de seleção dos estudos. Fortaleza, CE, Brasil, 2020.

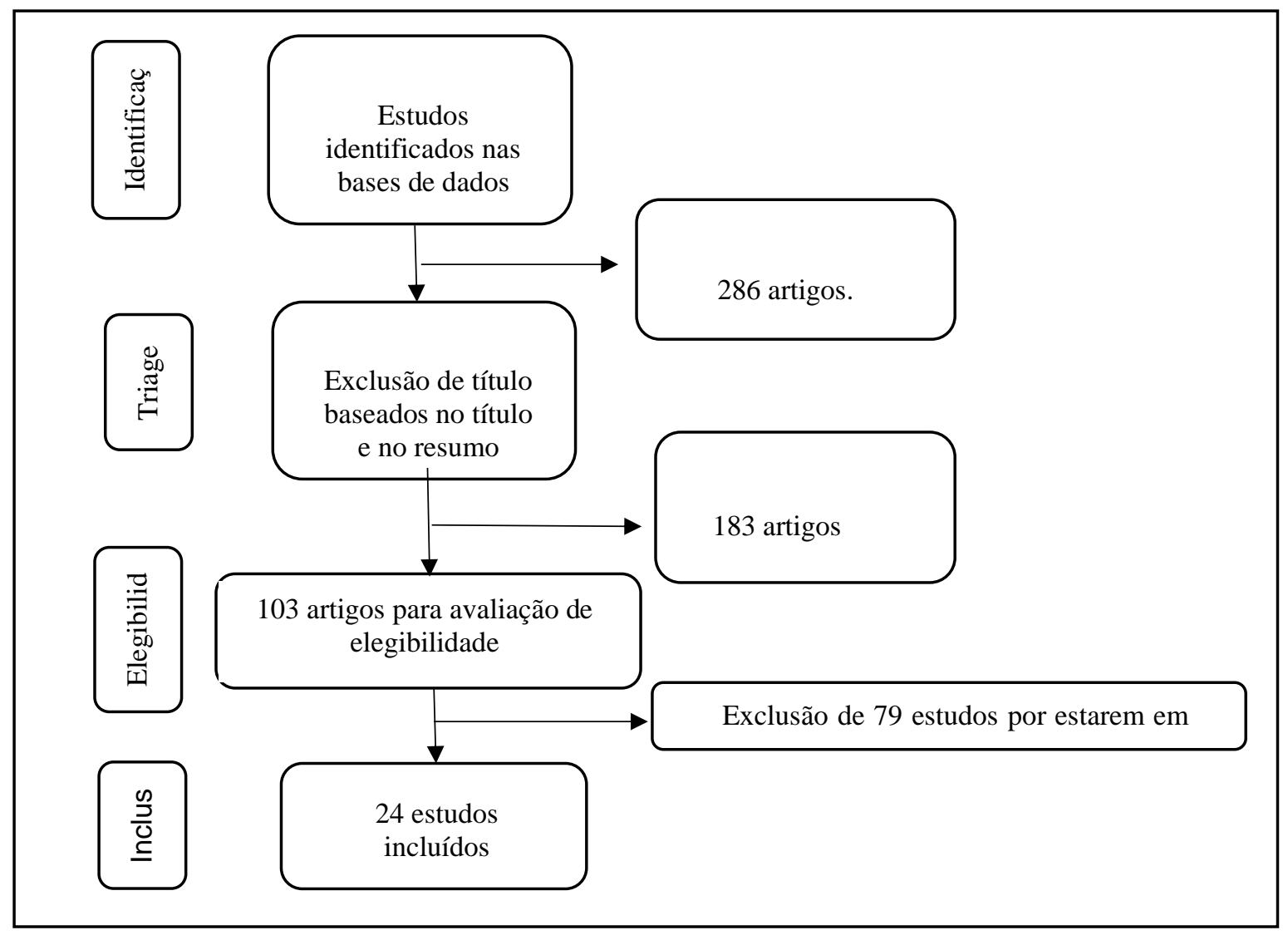

Fonte: Autores(2020).

Os quadros a seguir apresentam os artigos selecionados para o estudo aprofundado.

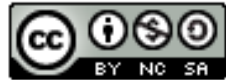


Citação (APA): Martins, R. T., Gabriel, I. de S., Silva, M. de L., \& Quental, O. B. de. (2020). Prevalência da violência contra a mulher no nordeste: uma questão de saúde pública. Brazilian Journal of Production Engineering, 6(7), 150-172.

Quadro 1. Base de dados SCIELO.

\begin{tabular}{|c|c|c|c|}
\hline Título & Autor & Ano & Objetivo \\
\hline $\begin{array}{c}\text { Da violência sexual e outras } \\
\text { ofensas contra a mulher com } \\
\text { deficiência. }\end{array}$ & $\begin{array}{l}\text { Passos, regina lucia; } \\
\text { telles, fernando } \\
\text { salgueiro passos; } \\
\text { oliveira, maria helena } \\
\text { barros de. }\end{array}$ & 2019 & $\begin{array}{l}\text { Analisar dois parâmetros que } \\
\text { sustentam a violência no Brasil: ser } \\
\text { mulher e com deficiência. Discute- } \\
\text { se a forma de como a deficiência } \\
\text { potencializa a invisibilidade social } \\
\text { das mulheres. O referencial teórico } \\
\text { trata da violência de gênero e da } \\
\text { deficiência, nos conceitos de } \\
\text { feminicídio, no campo de } \\
\text { deficiências e seus modelos e da } \\
\text { acessibilidade atitudinal e } \\
\text { invisibilidade. }\end{array}$ \\
\hline $\begin{array}{c}\text { Perfil dos parceiros íntimos de } \\
\text { violência doméstica: uma } \\
\text { expressão da questão social } \\
\text { brasileira } \\
\end{array}$ & $\begin{array}{c}\text { Gedrat, dóris cristina; } \\
\text { silveira, eliane fraga } \\
\text { da; almeida neto, honor } \\
\text { de. }\end{array}$ & 2020 & $\begin{array}{c}\text { Pesquisa características dos } \\
\text { parceiros íntimos que praticam } \\
\text { violência doméstica contra a } \\
\text { mulher. }\end{array}$ \\
\hline $\begin{array}{l}\text { Violência provocada pelo } \\
\text { parceiro íntimo entre usuárias } \\
\text { da Atenção Primária à Saúde: } \\
\text { prevalência e fatores } \\
\text { associados }\end{array}$ & $\begin{array}{l}\text { Doriana ozólio alves } \\
\text { rosa, renata cristina de } \\
\text { souza ramos, talita } \\
\text { munick vieira gomes, } \\
\text { elza machado de melo, } \\
\text { victor hugo melo } \\
\end{array}$ & 2019 & $\begin{array}{l}\text { A violência provocada por parceiro } \\
\text { íntimo é reconhecida mundialmente } \\
\text { como um problema de saúde } \\
\text { pública. O artigo investiga a } \\
\text { prevalência e os fatores associados } \\
\text { a esse tipo de violência. }\end{array}$ \\
\hline $\begin{array}{c}\text { Evolução da notificação de } \\
\text { violência sexual no Brasil de } \\
2009 \text { a } 2013 .\end{array}$ & $\begin{array}{l}\text { Gaspar, renato simões; } \\
\text { pereira, marina uchoa } \\
\text { lopes. }\end{array}$ & 2018 & $\begin{array}{c}\text { Analisar a evolução das } \\
\text { notificações de violência sexual no } \\
\text { Brasil entre } 2009 \text { e } 2013 \text {, dando } \\
\text { especial enfoque ao estupro. }\end{array}$ \\
\hline $\begin{array}{c}\text { Gestores de saúde e o } \\
\text { enfrentamento da violência de } \\
\text { gênero contra as mulheres: as } \\
\text { políticas públicas e sua } \\
\text { implementação em São Paulo, } \\
\text { Brasil. }\end{array}$ & $\begin{array}{l}\text { Batista, karina barros } \\
\text { calife; schraiber, lilia } \\
\text { blima; d'oliveira, ana } \\
\text { flávia pires lucas. } \\
\text { Gestores de saúde e o } \\
\text { enfrentamento da } \\
\text { violência de gênero } \\
\text { contra as mulheres: as } \\
\text { políticas públicas e sua } \\
\text { implementação em são } \\
\text { paulo, brasil. }\end{array}$ & 2018 & $\begin{array}{l}\text { Mapear as políticas públicas e as } \\
\text { propostas de organização } \\
\text { institucional de uma rede de } \\
\text { atenção integral, assim como } \\
\text { conhecer suas implementações nos } \\
\text { serviços, com destaque ao setor de } \\
\text { saúde, pelos relatos de gestores e } \\
\text { formuladores da política, } \\
\text { trabalhando-se a relação da prática } \\
\text { da gestão com o enunciado nas } \\
\text { políticas públicas, o peso dos } \\
\text { valores e da perspectiva pessoal } \\
\text { dos gestores e o peso do discurso } \\
\text { socialmente dominante nas } \\
\text { tomadas de decisão para a } \\
\text { implementação destas políticas. }\end{array}$ \\
\hline $\begin{array}{l}\text { Violência doméstica contra } \\
\text { mulheres rurais: práticas de } \\
\text { cuidado desenvolvidas por } \\
\text { agentes comunitários de saúde. }\end{array}$ & $\begin{array}{l}\text { Arboit, jaqueline et al. } \\
\text { Violência doméstica } \\
\text { contra mulheres rurais: } \\
\text { práticas de cuidado } \\
\text { desenvolvidas por } \\
\text { agentes comunitários } \\
\text { de saúde. }\end{array}$ & 2018 & $\begin{array}{l}\text { Conhecer as práticas de cuidado } \\
\text { desenvolvidas por agentes } \\
\text { comunitários de saúde na atenção } \\
\text { às mulheres em situação de } \\
\text { violência doméstica residentes em } \\
\text { áreas rurais. }\end{array}$ \\
\hline $\begin{array}{c}\text { Violência física grave entre } \\
\text { parceiros íntimos como fator de } \\
\text { risco para inadequação no } \\
\text { rastreio do câncer de colo de } \\
\text { útero. }\end{array}$ & $\begin{array}{l}\text { Rafael, ricardo de } \\
\text { mattos russo; moura, } \\
\text { anna tereza miranda } \\
\text { soares de. Violência } \\
\text { física grave entre } \\
\text { parceiros íntimos como } \\
\text { fator de risco para } \\
\text { inadequação no rastreio }\end{array}$ & 2017 & $\begin{array}{l}\text { Avaliar a ocorrência de violência } \\
\text { física grave entre parceiros íntimos } \\
\text { como fator de risco para } \\
\text { inadequação no rastreio do câncer } \\
\text { do colo do útero, }\end{array}$ \\
\hline
\end{tabular}


Citação (APA): Martins, R. T., Gabriel, I. de S., Silva, M. de L., \& Quental, O. B. de. (2020). Prevalência da violência contra a mulher no nordeste: uma questão de saúde pública. Brazilian Journal of Production Engineering, 6(7), 150-172.

\begin{tabular}{|c|c|c|c|}
\hline & $\begin{array}{c}\text { do câncer de colo de } \\
\text { útero. }\end{array}$ & & \\
\hline $\begin{array}{c}\text { Violência de gênero: } \\
\text { comparação da mortalidade por } \\
\text { agressão em mulheres com e } \\
\text { sem notificação prévia de } \\
\text { violência }\end{array}$ & $\begin{array}{c}\text { Barufaldi, laura } \\
\text { augusta et al. Violência } \\
\text { de gênero: comparação } \\
\text { da mortalidade por } \\
\text { agressão em mulheres } \\
\text { com e sem notificação } \\
\text { prévia de violência. }\end{array}$ & 2017 & $\begin{array}{l}\text { Descrever o perfil de mortalidade } \\
\text { por agressão em mulheres e } \\
\text { analisar se as vítimas de violência } \\
\text { notificadas apresentam taxas de } \\
\text { mortalidade por esse motivo mais } \\
\text { elevadas do que a população } \\
\text { feminina geral. }\end{array}$ \\
\hline $\begin{array}{l}\text { Domestic violence: } \\
\text { repercussions for women and } \\
\text { children. }\end{array}$ & $\begin{array}{l}\text { Arneiro, jordana brock } \\
\text { et al. Domestic } \\
\text { violence: repercussions } \\
\text { for women and } \\
\text { children. }\end{array}$ & 2017 & $\begin{array}{l}\text { Conhecer os significados atribuídos } \\
\text { pelas mulheres às repercussões da } \\
\text { experiência de violência doméstica. }\end{array}$ \\
\hline $\begin{array}{c}\text { Fatores associados à violência } \\
\text { contra mulheres profissionais } \\
\text { do sexo de dez cidades } \\
\text { brasileiras. }\end{array}$ & $\begin{array}{l}\text { Lima, francisca sueli } \\
\text { da silva et al. Fatores } \\
\text { associados à violência } \\
\text { contra mulheres } \\
\text { profissionais do sexo } \\
\text { de dez cidades } \\
\text { brasileiras. }\end{array}$ & 2017 & $\begin{array}{l}\text { Estimar a prevalência de violência } \\
\text { contra mulheres profissionais do } \\
\text { sexo, segundo natureza e } \\
\text { perpetrador, e identificar os fatores } \\
\text { associados. }\end{array}$ \\
\hline $\begin{array}{l}\text { Violência doméstica e familiar } \\
\text { contra a mulher: estudo de } \\
\text { casos e controles com vítimas } \\
\text { atendidas em serviços de } \\
\text { urgência e emergência. }\end{array}$ & $\begin{array}{l}\text { Garcia, leila posenato } \\
\text { et al. Violência } \\
\text { doméstica e familiar } \\
\text { contra a mulher: estudo } \\
\text { de casos e controles } \\
\text { com vítimas atendidas } \\
\text { em serviços de } \\
\text { urgência e emergência. }\end{array}$ & 2016 & $\begin{array}{l}\text { Identificar fatores associados ao } \\
\text { atendimento por violência } \\
\text { doméstica e familiar entre vítimas } \\
\text { atendidas em serviços de urgência e } \\
\text { emergência no Brasil. }\end{array}$ \\
\hline
\end{tabular}

\section{Fonte: Autores.}

Quadro 2. Base de dados LILACS

\begin{tabular}{|c|c|c|c|}
\hline Título & Autor & Ano & Objetivo \\
\hline $\begin{array}{c}\text { Direitos sexuais e } \\
\text { reprodutivos de mulheres } \\
\text { em situação de violência } \\
\text { sexual: o que dizem } \\
\text { gestores, profissionais e } \\
\text { usuárias dos serviços de } \\
\text { referência. }\end{array}$ & $\begin{array}{l}\text { Silva, Juliana Guimarães e; } \\
\text { Branco, July Grassiely de } \\
\text { Oliveira; Vieira, Luiza Jane } \\
\text { Eyre de Souza; Brilhante, } \\
\text { Aline Veras Morais; Silva, } \\
\text { Raimunda Magalhães da. }\end{array}$ & 2019 & $\begin{array}{l}\text { Analisar o acesso à atenção e a } \\
\text { garantia dos direitos sexuais e } \\
\text { reprodutivos de mulheres em } \\
\text { situação de violência sexual, }\end{array}$ \\
\hline $\begin{array}{l}\text { A institucionalização das } \\
\text { políticas públicas de } \\
\text { enfrentamento à violência } \\
\text { contra as mulheres no } \\
\text { Brasil. }\end{array}$ & $\begin{array}{c}\text { Martins, Ana Paula Antunes; } \\
\text { Cerqueira, Daniel Ricardo de } \\
\text { Castro; Matos, Mariana Vieira } \\
\text { Martins. }\end{array}$ & 2015 & $\begin{array}{c}\text { Destina-se a analisar a } \\
\text { espacialização dos serviços } \\
\text { especializados, considerando as } \\
\text { premissas da transversalidade das } \\
\text { políticas públicas, da } \\
\text { intersetorialidade e da } \\
\text { capilaridade previstas pelo Pacto } \\
\text { Nacional de Enfrentamento à } \\
\text { Violência contra a Mulher. }\end{array}$ \\
\hline $\begin{array}{c}\text { Impacto da violência na } \\
\text { qualidade de vida das } \\
\text { vitimadas. }\end{array}$ & Dias, Isabella de Andrade. & 2019 & $\begin{array}{l}\text { Verificar o impacto da violência } \\
\text { na qualidade de vida das vítimas, } \\
\text { analisando as consequências } \\
\text { físicas e psíquicas das agressões } \\
\text { exercidas contra elas. }\end{array}$ \\
\hline $\begin{array}{c}\text { Caracterização dos casos de } \\
\text { violência física contra } \\
\text { mulheres notificados na } \\
\text { Bahia. }\end{array}$ & $\begin{array}{l}\text { Dantas, Giselle de Santana } \\
\text { Vilasboas; Silva, Polyana Leal } \\
\text { da; Silva, Jaine Kareny da; } \\
\text { Rios, Marcela Andrade. }\end{array}$ & 2017 & $\begin{array}{c}\text { Descrever os casos de violência } \\
\text { física (VF) contra a mulher } \\
\text { notificados ao Sistema de } \\
\text { Informação de Agravos de }\end{array}$ \\
\hline
\end{tabular}


Citação (APA): Martins, R. T., Gabriel, I. de S., Silva, M. de L., \& Quental, O. B. de. (2020). Prevalência da violência contra a mulher no nordeste: uma questão de saúde pública. Brazilian Journal of Production Engineering, 6(7), 150-172.

\begin{tabular}{|c|c|c|c|}
\hline & & & $\begin{array}{l}\text { Notificação (SINAN) na Bahia, } \\
\text { nos anos de } 2009 \text { a } 2014 .\end{array}$ \\
\hline $\begin{array}{c}\text { Fatores associados à } \\
\text { violência contra mulher na } \\
\text { vida pregressa de mulheres } \\
\text { encarceradas. }\end{array}$ & $\begin{array}{l}\text { Fanger, Vanessa Cristina; } \\
\text { Santiago, Silvia Maria; Audi, } \\
\text { Celene Aparecida Ferrari. }\end{array}$ & 2019 & $\begin{array}{l}\text { Verificar a prevalência e os } \\
\text { fatores associados à violência na } \\
\text { vida pregressa das reeducandas da } \\
\text { Penitenciária Feminina de } \\
\text { Campinas-SP. }\end{array}$ \\
\hline $\begin{array}{l}\text { A violência contra a mulher } \\
\text { no sistema único de saúde. }\end{array}$ & $\begin{array}{c}\text { Cavalcanti, Gisélia de Moura } \\
\text { Bezerra; Amorim, Ana Vitória } \\
\text { Borges de; Queiroz, Gabriela } \\
\text { Silva de; Cruz, Natália } \\
\text { Mendes; Costa, Raissa Leite; } \\
\text { Bezerra, Klenia Felix de } \\
\text { Oliveira. } \\
\end{array}$ & 2020 & $\begin{array}{l}\text { Caracterizar a produção científica } \\
\text { acerca da violência contra mulher } \\
\text { e suas repercussões sociais, em } \\
\text { periódicos online no âmbito da } \\
\text { saúde, publicados no período de } \\
2011 \text { a } 2016 .\end{array}$ \\
\hline $\begin{array}{l}\text { Violência contra a mulher: } \\
\text { como os profissionais na } \\
\text { atenção primária à saúde } \\
\text { estão enfrentando esta } \\
\text { realidade? }\end{array}$ & $\begin{array}{c}\text { Santos, Silvana Cavalcanti dos; } \\
\text { Barros, Patrícia de } \\
\text { Albuquerque; Delgado, } \\
\text { Rafaella França de Araújo; } \\
\text { Silva, Luiza Vanessa de Lima; } \\
\text { Carvalho, Valdirene P. da } \\
\text { Silva; Alexandre, Ana Carla } \\
\text { Silva. } \\
\end{array}$ & 2018 & $\begin{array}{l}\text { Objetiva identificar as formas de } \\
\text { assistência prestada pelos } \\
\text { profissionais da atenção primaria } \\
\text { à mulher vítima de violência no } \\
\text { município de Buíque (PE). }\end{array}$ \\
\hline $\begin{array}{c}\text { Preditores da violência } \\
\text { física contra mulheres } \\
\text { usuárias da atenção primária } \\
\text { à saúde. }\end{array}$ & $\begin{array}{l}\text { Leal, Islanne Soares; Siqueira, } \\
\text { Vitória de Barros; Campos, } \\
\text { Maria Elda Alves de Lacerda; } \\
\text { Melo, Rosana Alves de; } \\
\text { Fernandes, Flávia Emília } \\
\text { Cavalcante Valença. }\end{array}$ & 2017 & $\begin{array}{l}\text { Avaliar a ocorrência da violência } \\
\text { física perpetrada contra mulheres } \\
\text { usuárias da Atenção Primária à } \\
\text { Saúde e os fatores associados. }\end{array}$ \\
\hline $\begin{array}{c}\text { Relação entre a violência e a } \\
\text { saúde mental das mulheres } \\
\text { no Brasil: análise das } \\
\text { políticas públicas. }\end{array}$ & $\begin{array}{l}\text { Medeiros, Mariana Pedrosa de; } \\
\text { Zanello, Valeska. }\end{array}$ & 2018 & $\begin{array}{l}\text { Analisar se, e como, as políticas } \\
\text { públicas desenvolvidas para as } \\
\text { mulheres e aquelas resultantes da } \\
\text { Reforma Psiquiátrica dialogam } \\
\text { entre si no que tange ao tema dos } \\
\text { impactos da violência na saúde } \\
\text { mental das mulheres. }\end{array}$ \\
\hline $\begin{array}{c}\text { Sob a sombra da } \\
\text { maternidade: gravidez, } \\
\text { ideação suicida e violência } \\
\text { por parceiro íntimo }\end{array}$ & $\begin{array}{l}\text { Fonseca-Machado, Mariana de } \\
\text { Oliveira; Alves, Lisiane } \\
\text { Camargo; Haas, Vanderlei } \\
\text { José; Monteiro, Juliana } \\
\text { Cristina dos Santos; Gomes- } \\
\text { Sponholz, Flávia. } \\
\end{array}$ & 2015 & $\begin{array}{l}\text { Identificar a associação entre } \\
\text { violência por parceiro íntimo e } \\
\text { indicativo de ideação suicida } \\
\text { durante a atual gestação. }\end{array}$ \\
\hline $\begin{array}{l}\text { Violência sexual contra a } \\
\text { mulher: histórico e conduta }\end{array}$ & $\begin{array}{l}\text { Porto, Maria Laura; Amaral, } \\
\text { Waldemar Naves do. }\end{array}$ & 2014 & $\begin{array}{l}\text { Análise do histórico da violência } \\
\text { contra a mulher desde sua gênese } \\
\text { até a situação atual do } \\
\text { enfrentamento a violência sexual } \\
\text { no Brasil, através de políticas } \\
\text { governamentais de atendimento a } \\
\text { essas vítimas. }\end{array}$ \\
\hline $\begin{array}{l}\text { Violência contra mulher: } \\
\text { concepções e práticas de } \\
\text { profissionais de serviços } \\
\text { públicos }\end{array}$ & $\begin{array}{c}\text { Souza, Tatiana Machiavelli } \\
\text { Carmo; Rezende, Fernanda } \\
\text { Ferreira. }\end{array}$ & 2018 & $\begin{array}{l}\text { Investigar as concepções e } \\
\text { práticas de profissionais de saúde } \\
\text { acerca do fenômeno da violência } \\
\text { contra mulher }\end{array}$ \\
\hline $\begin{array}{l}\text { Representação da violência } \\
\text { doméstica contra mulheres } \\
\text { entre profissionais de saúde: } \\
\text { idade como atributo de } \\
\text { diferenciação. }\end{array}$ & $\begin{array}{l}\text { Silva, Camila Daiane; Gomes, } \\
\text { Vera Lúcia de Oliveira; } \\
\text { Oliveira, Denize Cristina de; } \\
\text { Amarijo, Cristiane Lopes; } \\
\text { Acosta, Daniele Ferreira; } \\
\text { Mota, Marina Soares }\end{array}$ & 2016 & $\begin{array}{l}\text { Comparar, segundo a idade, as } \\
\text { representações da violência } \\
\text { doméstica contra a mulher entre } \\
\text { técnicos de enfermagem e agentes } \\
\text { comunitários de saúde, atuantes } \\
\text { em unidades de saúde da família, }\end{array}$ \\
\hline
\end{tabular}


Citação (APA): Martins, R. T., Gabriel, I. de S., Silva, M. de L., \& Quental, O. B. de. (2020). Prevalência da violência contra a mulher no nordeste: uma questão de saúde pública. Brazilian Journal of Production Engineering, 6(7), 150-172.

\section{RESULTADOS E DISCUSSÃO}

A partir da leitura atenta e minuciosa dos artigos selecionados para o estudo em profundidade foi possível traçar um retrato fiel acerca das características e peculiaridades da violência contra a mulher no país. Os principais resultados são apresentados a seguir.

A maior parte das vítimas tem até 40 (quarenta) anos de idade. Em apenas 10\% dos artigos foram apresentados relatos de violência a mulheres mais jovens, com idade entre 0 e 18 anos. Por outro lado, $6 \%$ dos autores consultados relataram ocorrências de violência doméstica e familiar contra idosas, mulheres com mais de $60 \%$, sendo que a vítima mais idosa tinha, por ocasião da agressão, 81anos. Estes resultados coadunam com o estudo empreendido por Silva (2003), segundo o qual a maior prevalência de mulheres vítimas de violência doméstica e familiar se encontra na faixa etária acima de 30 anos (Tabela 3 ).

Tabela 3. Faixa etária das vítimas.

\begin{tabular}{cc}
\hline Faixa etária & Percentual \\
\hline Entre 0 e 20 anos & $10 \%$ \\
\hline Entre 21 e 40 anos & $64 \%$ \\
\hline Entre 41 e 60 anos & $19 \%$ \\
\hline Acima de 61 anos & $7 \%$ \\
\hline
\end{tabular}

$$
\text { Fonte: Autores }
$$

Quanto à raça, levantou-se que $22 \%$ das mulheres vítimas de violência se autodeclararam da cor branca, 65\% de cor parda e apenas 13\% declararam-se negras (Tabela 4).

Tabela 4. Raça das vítimas.

\begin{tabular}{cc}
\hline Raça & Percentual \\
\hline Branca & $22 \%$ \\
\hline Parda & $65 \%$ \\
\hline Negra & $13 \%$ \\
\hline
\end{tabular}

Fonte: Autores.

Os resultados revelaram que a maior parte das vítimas possui baixa escolaridade: $62 \%$ das mulheres eram, por ocasião do fato, analfabetas ou haviam estudado somente até o ensino fundamental e apenas 38\% tinham finalizado o ensino médio ou superior. Estes resultados são muito semelhantes aos obtidos por Vieira et al. (2013), cujo estudo destinado a identificar a prevalência e fatores associados à sobreposição dos diferentes tipos de violência contra a mulher, realizado em Fortaleza, Ceará, encontrou taxas percentuais de $67 \%$ e 33\%, respectivamente (Tabela 5).

Tabela 5. Escolaridade das vítimas.

\begin{tabular}{c|c}
\hline Escolaridade & Percentual (\%) \\
\hline Analfabetas/ ensino fundamental & 62 \\
Ensino médio/superior & 38 \\
\hline
\end{tabular}

Fonte: Autores.

Devido à violência que sofrem em seus lares muitas mulheres são obrigadas a sair de casa e buscar refúgio em abrigos criados pelo poder público, onde podem permanecer temporariamente até que as autoridades tomem as medidas necessárias para resguardar sua segurança, como a concessão de medidas protetivas pelo poder judiciário, as quais podem culminar com a retirada coercitiva do agressor do lar ou mesmo com sua prisão preventiva. Os artigos analisados, ao se debruçarem sobre a questão da institucionalização de mulheres vítimas 

nordeste: uma questão de saúde pública. Brazilian Journal of Production Engineering, 6(7), 150-172.

de violência apontaram que $36 \%$ das vítimas pesquisadas eram donas de casa (36\%), $21 \%$ eram domésticas, $7 \%$ estudantes, $14 \%$ desempregadas e outros $3 \%$ eram professoras, funcionária públicas ou comerciantes. Constatou-se que a imensa maioria das vítimas (78\%) eram pobres e dependiam economicamente de seus algozes, o que demonstra a necessidade de implementação de políticas públicas que possam assegurar a essas mulheres condições financeiras para romper o ciclo vicioso da violência perpetrada em suas casas.

Sobre a espécie de violência praticada contra a mulher constatou-se que a categoria com maior quantidade de relatos/ocorrências, de acordo com os artigos analisados, foi a violência psicológica, seguida da violência física (Tabela 6).

Tabela 6. Tipos de violência perpetrada. (\%)*.

\begin{tabular}{cc}
\hline Tipo & Percentual \\
\hline Psicológica & $74 \%$ \\
Física & $62 \%$ \\
Moral (abandono, negligencia, etc.) & $48 \%$ \\
Sexual & $8 \%$ \\
\hline
\end{tabular}

*Valores superam os $100 \%$ pois a maior parte dos artigos citou mais de um tipo de violência.

Sobre os agressores, $72 \%$ destes, segundo os dados obtidos, são os homens com os quais as vítimas convivem maritalmente (maridos, companheiros, amantes, etc.). Resultado ainda mais esclarecedor foi encontrado por Mesquita (2009), que ao analisar a afinidade da vítima com o autor da violência encontrou que $83 \%$ dos agressores são pessoas que tem ou tiveram uma relação afetiva amorosa com a mulher.

Analisando-se os dados da pesquisa percebeu-se entre as mulheres vítimas de violência dois tipos básicos de organização familiar: a família nuclear (constituída por dois adultos e pelos filhos biológicos do casal) e a família reconstituída (formadas por dois adultos e por filhos com laços biológicos conectados a apenas um dos adultos), originando a figura do padrasto ou madrasta: $64 \%$ das mulheres analisadas declararam pertencer a famílias nucleares e $36 \%$ a famílias reconstituídas. Este dado é relevante, conforme Rabello e Júnior (2007), pois as famílias nucleares apresentaram cinco vezes mais chances de a mulher ser vítima de violência em comparação com as famílias reconstituídas, o que ocorre, segundo os autores, pelo fato de que parentes sem consanguinidade interferem com maior frequência sobre a dinâmica do ciclo de violência, contribuindo para o seu rompimento (Gráfico 1).

Gráfico 1. Organização familiar

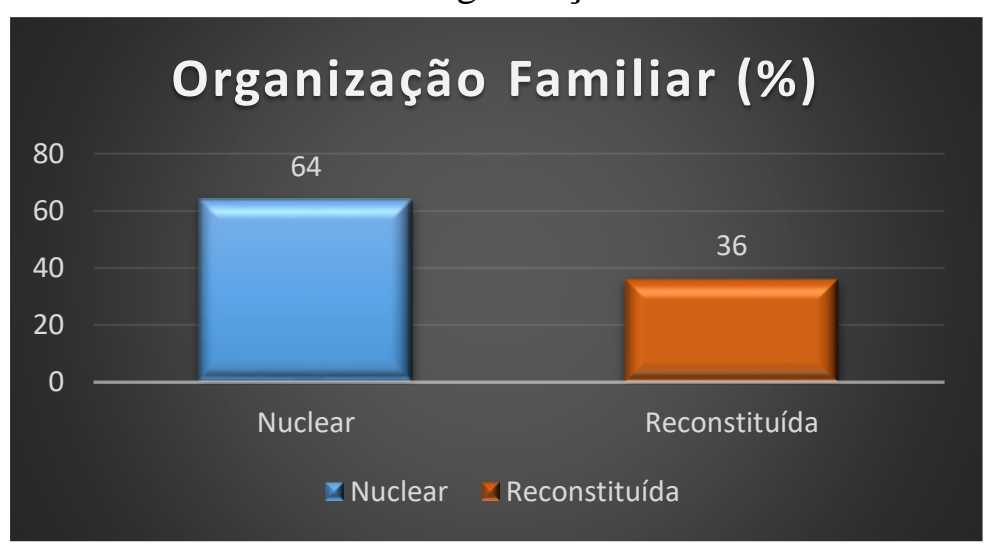

Fonte: Autores.

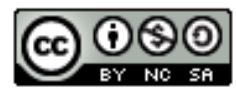



nordeste: uma questão de saúde pública. Brazilian Journal of Production Engineering, 6(7), 150-172.

Quanto ao uso de substâncias psicoativas por membros da família, 80\% dos artigos pesquisados informaram que o agressor fazia uso regular de substancias psicoativas, como álcool, drogas lícitas com venda controlada ou mesmo drogas ilícitas como maconha ou crack. Pesquisa realizada em João Pessoa (PB), por Rabello e Júnior (2007), revelou que as famílias das mulheres agredidas tinham maior frequência de membros usuários de drogas $(90,8 \%)$ em comparação com as de mulheres não agredidas. Já segundo Meneguel et al. (2003), embora muitos agressores façam uso de maconha ou crack, a droga que mais afeta negativamente a harmonia familiar é mesmo o álcool, por ser aceito pela sociedade, o que permite o consumo em grande quantidade.

Especificamente sobre o impacto da violência contra a mulher na saúde pública verificou-se que o serviço de Atenção Primária à Saúde (APS) é muito procurado por mulheres em situação de violência. Este resultado está em harmonia com a conclusão apontada por Andrade (2009), segundo a qual aproximadamente $30 \%$ dos motivos que levam as mulheres a procurarem os serviços de saúde estão vinculados à violência. Entretanto tal violência, no sistema de saúde nacional, não representa uma demanda explícita, isto é, a mulher reluta em contar para o médico ou enfermeiro, por exemplo, que a fratura em seu braço foi resultado de violência doméstica e, não raras vezes, o profissional de saúde não pergunta a respeito, limitando-se a solicitar os exames pertinentes e a prescrever o tratamento adequado, o que explica a subnotificação de casos de violência por parte de profissionais do SUS.

Um achado de grande importância obtido a partir da análise dos artigos selecionados revelou a elevada prevalência da violência doméstica ou familiar entre usuárias dos serviços básicos de saúde, o que vai ao encontro de estudos nacionais, a exemplo do elaborado por Schraiber et al., (2007) e do produzido por Deslandes et al., (2000) e internacionais, como o desenvolvido pela Organização Pan Americana de Saúde (OPAS, 2002).

Também foi possível comprovar que a violência afeta sobremaneira a saúde feminina: dobra o risco da não realização de exames essenciais, como o que possibilita o rastreio do câncer de colo de útero, e quadruplica os riscos para a inadequação do exame, se comparado com mulheres não sujeitas à violência de gênero. Também contribui para a má qualidade do prénatal.

De acordo com Barufaldi, et al., (2017), a violência contra a mulher repercute na ausência de saúde e na falta de qualidade de vida das mesmas e tem sido associada à frequente procura pelos serviços de saúde. Plichta mostra associações da violência com efeitos imediatos como lesões e traumas que levam aos serviços de emergência, tanto quanto efeitos indiretos e de longo prazo, como as dores crônicas, problemas gastrointestinais, fibromialgias, doenças sexualmente transmissíveis, infecções urinárias de repetição, problemas com menstruação e disfunções sexuais, entre outras. No mesmo estudo, ainda chama a atenção o comprometimento da saúde mental destas usuárias. As mulheres que sofreram violência sexual são 2,3 vezes mais propensas a desenvolver distúrbios relacionados ao álcool e 2,6 vezes mais propensos a sofrer de depressão ou ansiedade.

Outro achado extremamente relevante para os propósitos deste trabalho comprovou que as mulheres em situação de violência que procuram assistência médica não são, de modo geral,

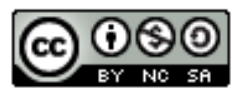



nordeste: uma questão de saúde pública. Brazilian Journal of Production Engineering, 6(7), 150-172.

atendidas por profissionais sensíveis quanto à abordagem do problema. A grande maioria dos artigos analisados certificou que os profissionais de saúde compreendem perfeitamente a necessidade de se acolherem as mulheres vítimas da violência de gênero, contudo sentem-se impotentes ou com medo de lidarem com o fenômeno, muitas vezes por falta de informação ou qualificação profissional.

Os artigos revelaram os principais espaços utilizados pelos serviços de saúde para o reconhecimento e identificação da violência doméstica e familiar contra a mulher, exibidos no gráfico 2.

Gráfico 2. Espaços utilizados pelos serviços de saúde para a identificação da violência.

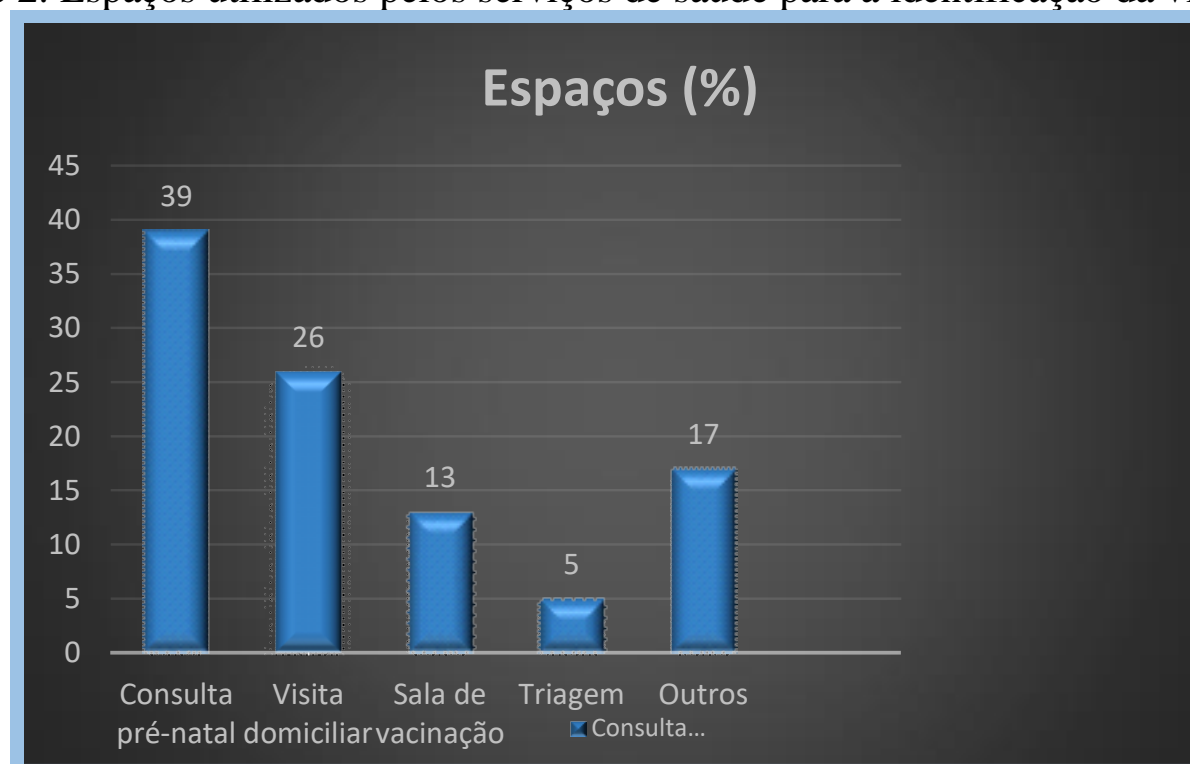

Fonte: Autores.

\section{CONSIDERAÇÕES FINAIS}

A violência contra a mulher ocorre em todo o mundo, mas no Brasil os dados disponíveis apresentam um cenário preocupante e perturbador. Anualmente milhares de casos de violência contra a mulher, em suas mais variadas formas (estupro, feminicídio, tortura psicológica, etc.) são registrados no país. Trata-se inegavelmente de um grave problema social, mas que a cada dia se torna também um grave problema de saúde pública em consequência da elevada procura por serviços de saúde e assistência médica pelas vítimas a fim de tratar os traumas físicos e psicológicos resultantes da violência sofrida.

Após a realização da pesquisa pode-se afirmar que os serviços ofertados pela Atenção Primária à Saúde (APS) são imprescindíveis para a identificação de situações de violência contra as mulheres. Contudo, para que processo de identificação seja exitoso e possam as vítimas serem devidamente encaminhadas para a rede de proteção social é preciso que os profissionais de saúde responsáveis pelo atendimento sejam adequadamente capacitados quanto à questão da violência contra a mulher.

Constatou-se, após a consulta à literatura disponível, que muitos médicos, enfermeiros e agentes comunitários de saúde não estão familiarizados com o tema, gerando desinformação e desconhecimento acerca das questões de gênero e direitos das mulheres, além da falta de

\section{@ $\odot \Theta \odot$}



nordeste: uma questão de saúde pública. Brazilian Journal of Production Engineering, 6(7), 150-172.

sensibilidade para abordar o problema. Indubitavelmente quanto mais deficiente a qualificação e sensibilização do profissional, pior o cuidado dispensado à paciente. Neste sentido, para aprimorar a assistência prestada, é necessário fortalecer o diálogo entre as vítimas e os profissionais de saúde, providência que resultará, certamente, em melhoria no atendimento e acompanhamento das pacientes.

É preciso ressaltar, por outro lado, que há também profissionais que identificam prontamente a situação de violência, mas se sentem impotentes diante de problemas tão complexos quanto a violência de gênero, mais um sinal de falta de capacitação específica para agir diante de situações de violência contra a mulher. Outro achado oriundo da pesquisa merece destaque: muito frequentemente a própria vítima não considera que um problema de violência doméstica deva ser tratado e reconhecido como problema relacionado ao sistema de saúde. Muitas mulheres preferem calar, não verbalizar acerca da violência de que são vítimas, por receio de represálias ou vergonha, contribuindo para a invisibilidade do fenômeno junto aos órgãos oficiais.

Entretanto a violência contra a mulher não pode ser ignorada. A pesquisa realizada revelou que muito do absenteismo feminino no tocante à realização de exames preventivos contra o desenvolvimento de neoplasias se deve a situações de violência, evidenciando de forma cristalina a associação entre a violência íntima e a dificuldade de acesso aos serviços de saúde, principalmente os que exigem frequência com certa regularidade. Concluiu-se que situações de violência geram baixa autoestima e vergonha, além do medo, o que contribui para aumentar o isolamento e dificulta o cuidado com a própria saúde.

A autora acredita que todos os objetivos propostos foram plenamente alcançados. Para estudos futuros sugere-se a realização de pesquisas destinadas ao desenvolvimento de estratégias pelos gestores dos serviços de saúde para a prevenção da violência de gênero, como as visitas domiciliares, por exemplo, que podem favorecer a identificação de vulnerabilidades e riscos no próprio lar da paciente, além de estreitar vínculos entre a equipe multiprofissional de saúde e a usuário do serviço.

\section{REFERÊNCIAS}

Alves, M. H. M., \& Evanson, P. (2013) . Vivendo no fogo cruzado: moradores de favela, traficantes de droga e violência policial no Rio de Janeiro. São Paulo, Editora Unesp.

Alves, R. E. O., \& Leal, L. V. M. (2013). Violencia psicológica e a saúde da mulher. Disponível em:

http://www.fesurv.br/imgs/13\%20VIOL\%C3\%8ANCIA\%20PSICOL\%C3\%93GICA\%20E\% 20A\%20SA\%C3\%99ADE\%20DA\%20MULHER\%20ED.pdf. Acesso em: 03 mar. 2019.

Amaral, C. C. G. (2002) Violência em delegacias da mulher no Nordeste. In: Gênero e Cidadania. Coleção Encontros. PAGU/Núcleo de Estudos de Gênero.

Andrade, C.J.M. (2009). As equipes de saúde da família e a violência doméstica contra a mulher: um olhar de gênero. São Paulo: Escola de Enfermagem, Universidade de São Paulo.

Borin, T.B. (2007). Violência doméstica contra a mulher: percepções sobre violência em mulheres agredidas. Dissertação. Faculdade de Filosofia, Ciências e Letras de Ribeirão Preto. Ribeirão Preto, São Paulo.

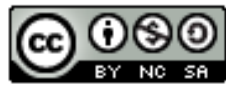


Citação (APA): Martins, R. T., Gabriel, I. de S., Silva, M. de L., \& Quental, O. B. de. (2020). Prevalência da violência contra a mulher no nordeste: uma questão de saúde pública. Brazilian Journal of Production Engineering, 6(7), 150-172.

Bourdieu, P. (2003). A dominação Masculina. $3^{\text {a }}$ Ed. Rio de Janeiro: Bertrand Brasil, 2003.

Brasil, Ministério da Saúde. Portaria n ${ }^{\circ}$ 104, de 25 de Janeiro de 2011. Define as terminologias adotadas em legislação nacional, conforme o disposto no Regulamento Sanitário Internacional 2005 (RSI 2005), a relação de doenças, agravos e eventos em saúde pública de notificação compulsória em todo o território nacional e estabelece fluxo, critérios, responsabilidades e atribuições aos profissionais e serviços de saúde. Disponível em: < http://bvsms.saude.gov.br/bvs/saudelegis/gm/2011/prt0104_25_01_2011.html> Acesso em: 25 abr. 2019.

Carneiro, .A.A., \& Fraga, C.K. (2012). A Lei Maria da Penha e a proteção legal à mulher vítima em São Borja no Rio Grande do Sul: da violência denunciada à violência silenciada. Serv. Soc. Soc. São Paulo, n. 110, p. 369-393.

Coelho, E. B. S., Silva, A. C. L. G., \& Lindner, S. R. (2014). Violência: definições e tipologias. Universidade Federal de Santa Catarina. Florianópolis.

Day, V. P. et al. (2020). Violência Doméstica e suas diferentes manifestações. Rev. psiquiatr. Rio Gd. Sul, Porto Alegre, v. 25, suppl. 1, 2003. Disponível em: http://www.scielo.br. Acesso em: 09 jun. 2020.

Deslandes, S.F.; Gomes, R.; \$ Silva, C.M.F.P. (2000). Caracterização dos casos de violência doméstica contra a mulher atendidos em dois hospitais públicos do Rio de Janeiro. Cad. Saúde Pública, v, 16, n. 1.

Dias, S. P. A. (2019). Um breve histórico da violência contra a mulher. 2010. Disponível: http://araretamaumamulher.blogs.sapo.pt/16871.html. Acesso em: 01 mar.

Gil, A. C. (2010). Como elaborar projetos de pesquisa. 5. ed. São Paulo: Atlas, 184p.

Lakatos, E. M., \& Marconi, M. A. (2010). Fundamentos de metodologia científica: Técnicas de pesquisa. 7 ed. - São Paulo: Atlas.

Leite, M. T. S., Figueiredo, M. F. S., Dias, O. V., Vieira, M. A., Souza, L. P. S., \& Mendes, D. C. (2014). Reports of violence against women in different life cycles. Rev. Latino-Am. Enfermagem; 22(1):85-92.

Lucena, K. D. T et al. (2017) Association between domestic violence and women's quality of life. Rev. Latino-Am. Enfermagem, Ribeirão Preto, v. 25, e2901.

Nascimento, P. C. (2004). Violência doméstica contra a mulher: Serviço Social no espaço do CEVIC. Disponível em: http://tcc.bu.ufsc.br/Ssocial287481.PDF. Acesso em: 20 jun. 2020.

Neto, J. S., Bezerra, C. R. M., Fernandes, N. P., Medeiros, R. M., SÁ, S. A. M., \& Pinto, D. S. (2015) Violência contra a mulher no contexto da saúde pública. Rev. Ciênc. Saúde Nova Esperança, v. 13, n. 2, p. 60-65.

Organização Panamericana de Saúde (OPAS). Informe mundial sobre la violência y la salud: resumen. Washington; 2002.

Rocha, M. G. G., \& Souza, J. L. C. (2013) Lei Maria da Penha Frente a Um dos Limites de sua Aplicabilidade. In: Daniel Chaves de Brito; Jaime Luiz Cunha de Souza. (Org.). Na Periferia do Policiamento: direitos humanos, violência e práticas policiais. $1^{\mathrm{a} e d . B e l e ́ m: ~ P a k a-T a t u . ~}$

Rosa, R. et al. (2010). Violence: concept and experience among health sciences undergraduate students. Interface - Comunic., Saude, Educ., v.14, n.32, p.81-90, jan./mar. 
Santiago, R. A., \& Coelho, M. T. A. D. (2011). A Violência contra a mulher numa perspectiva histórica e cultural.

Disponível: https://repositorio.ufba.br/ri/bitstream/ri/5234/1/A\%20VIOL\%C3\%8ANCIA\%20CONTRA\% 20A\%20MULHER\%20NUMA\%20PERSPECTIVA\%20HIST\%C3\%93RICA\%20E\%20CUL TURAL.pdf. Acesso em 01 mar. 2019.

Schraiber, L.B., D’Oliveira, A.F.P.L., Couto, M.T., Hanada, H., Kiss, L.B., \& Durand, J.G. et al. (2007). Violência contra mulheres entre usuárias de serviços públicos de saúde da Grande São Paulo. Rev Saúde Pública, v. 41, n. 3.

Tavares, O. (2011). Violência Conjugal - Dados sociodemográficos, comportamentos e crenças associados, "Fragmentos de um Amor menor". Dissertação de mestrado não publicada, Portalegre, Escola Superior de Educação.

Viana, A., Lira, M., Vieira, M., Sarmento, S., \& Souza, A. (2018). Violência contra a mulher. Revista de Enfermagem UFPE on line. v. 12. p. 923-929.

Vilela, O. (1997). A Violência no mundo atual. São Paulo: Loyola. 